\title{
Strengthening Civic-Mindedness and Democratic Commitment through Engaged Pedagogies
}

\author{
Ulla Hasager ${ }^{1}$, Ingrid Geier ${ }^{2}$ \\ ${ }^{1}$ University of Hawai ' $i$ at Mānoa, USA \\ ${ }^{2}$ Salzburg University of Teacher Education, Austria
}

\begin{abstract}
Service learning and active-citizenship learning address equity issues and help students strengthen their civic-mindedness and democratic commitment to society. Through working with communities, they gain experience and develop skills as they contribute to the common good. This paper presents research with undergraduate students regarding the impact of engaged pedagogies on attitudes centered around a culture of democracy, particularly civic-mindedness and orientation towards the common good. The research uses a mixed-method design and combines a quantitative survey (7 level Likert Scale) with focus group discussions. Fifty-five service-learning students from the University of Hawai'i at Mānoa and 95 students practicing active-citizenship learning at Salzburg University of Teacher Education took part in the study. The analysis integrates results from the survey with qualitative data from 23 focus group discussions. Findings show that both pedagogies in the two samples significantly support a culture of democracy. The authors find that engaged pedagogies can help ensure inclusive and equitable quality education and promote lifelong learning, when student projects engage in problem-solving in collaboration with the communities.
\end{abstract}

\section{Introduction}

Social engagement has become an important requirement for universities. As tertiary educational institutions, they are increasingly in communication with their surrounding community and society overall, and institutions of higher education are taking on social responsibility as their third academic mission [1], [2]. In addition to teaching and basic research, universities and other educational institutions can and must contribute to society in multiple ways. In order to support students in finding their role in society, pedagogies such as service learning (SL) and active-citizenship learning (ACL) done right - can play important roles.
This study is specifically focusing on the impact of engaged pedagogies on attitudes centered around civic-mindedness and orientation towards the common good - both key attitudinal components of a culture of democracy that many of us consider a precondition for a good society, protection of human rights, and perhaps even the future of humanity and Island Earth.

\section{Cultivating responsibility}

Concern about securing environmental and social sustainability has again brought a vision of lifelong learning to the forefront [1]. Beginning in the 1990s, global educational policy makers were increasingly again paying attention to a holistic vision of education, which not only focused on academic and practical skills. A 1996 report to the International Commission on Education for the Twenty-first Century, titled "Treasure Within" [3] outlined a holistic vision of education based on four interrelated pillars of learning (see Figure 1).

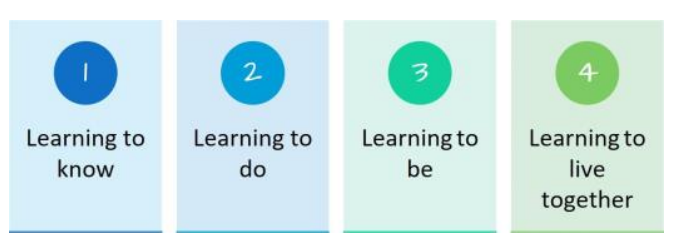

Figure 1. The four pillars of learning [3]

The strength of this four pillars-model is that it not only addresses learning in schools, but also in the workplace as well as in the private and public spheres [3], [4]. By including pillars in education focused on "learning to be" and "learning to live together," the model conveys a strong humanistic idea of education, which continues to influence our thinking, pedagogies, and education policies. 
The first pillar, learning to know, is about getting to know methods and concepts to provide a basis to help tackle the complexities of the world. The second pillar, learning to do, is about enabling students to act in a self-confident way, to contribute to the world, and interact with others. The third pillar, learning to be, emphasizes improving self-awareness and self-esteem to develop one's own personality and individuality. Finally, the fourth pillar, learning to live together, is about democratic awareness, human dignity and respecting human rights.

The humanistic educational focus on how we can shape education to create a better future is both meaningful and necessary today when we face a global reality of growing populism, climate crisis, and even a pandemic. It is clear that education must include emotional, social and ethical learning, as Delors convincingly argues [3], [4].

It is no surprise then that we today find that institutions of higher education as well as accrediting organizations increasingly are focusing on what has become known as a "third mission" [1]. While the first mission emphasizes teaching and qualifying human capital, and the second mission concentrates on research and the production of knowledge, the third mission inspires universities to find ways to engage with societal needs and different socio-economic contexts.

Centering students, engaged pedagogies such as service learning and active-citizenship learning focus on active involvement in society. They often aim at creating learning opportunities for students to develop their competences as informed and active citizens.

In 2012 the United States National Task Force on Civic Learning and Democratic Engagement addressed the urgent need of a civic mission in higher education:

"It is time to bring two national priorities - career preparation and increased access and completion rates - together in a more comprehensive vision with a third national priority: fostering informed, engaged, responsible citizens. Higher education is a space where that triad of priorities can cohere and flourish.... [A] socially cohesive and economically vibrant [...] democracy and a viable, just global community require informed, engaged, open-minded, and socially responsible people committed to the common good and practiced in "doing" democracy. In a divided and unequal world, education can provide opportunities to develop each person's full talents, equip graduates to contribute to economic recovery and innovation, and cultivate responsibility to a larger common good. Achieving that goal will require that civic learning and democratic engagement be not sidelined but central. Civic learning needs to be an integral component of every level of education." [5 pp. 13-14].

\section{Engaged pedagogies}

Service learning, which by now is a wide-spread pedagogy, combines social commitment with expert knowledge. Thus, methodological as well as social competence is acquired and enhanced. In this way students can react to societal requirements and problems and - by assuming social responsibility engage intensely with such issues. This kind of learning supports character formation, because with the combination of practical learning experiences and theoretical lesson content, key competencies are often acquired.

Active-citizenship learning is fundamentally similar to service learning, but it specifically takes its outset in self-regulated learning [6]. It is based on citizenship in accordance with human rights. Students create their own projects, which should represent a personal challenge for them. They formulate learning objectives for themselves and goals for what they want to achieve with the communities they work in, and they apply their projects in socially relevant contexts. Therefore, students strengthen their individual and collective goals (like autonomy, responsibility, or ability to reflect).

Both pedagogies aim to develop democratic and intercultural competence, while allowing students to develop their knowledge, skills, and personhood. This is mainly accomplished by bringing students into the communities, where they often take on responsibilities and become autonomous social players for the common good.

A key question in this context is how to go one step further and combine volunteering and civic engagement with knowledge, skills, and political understanding [7]. Learning experiences must be complemented by social engagement and, even more importantly, focus on democratic values and deepen an understanding of why that is politically important for a culture of democracy [8].

There are multiple possibilities for students to contribute to the social, cultural, ecological, economic, health, and political fields of our communities, but sustainability, equity, diversity, and inclusion must always be at the center of engagement projects that aim to enable a culture of democracy.

At University of Hawai'i at Mānoa, the servicelearning pedagogy is part of all disciplines and reaches all aspects of society. The best projects are those that are devised and coordinated by the communities themselves or in close, true, partnership with the communities, encouraging and securing lifelong learning opportunities for all stakeholders 
from students to faculty, administrators, and community partners. Recognizing the need for interdisciplinary collaboration across all institutions and communities, connecting indigenous and local knowledge with traditional academic disciplinary knowledge, is necessary to overcome the capacious issues facing us today. Engagement and communitybased research span from taking care of the cultural sites, to food production, working with run-away youth, to building bridges between ethnic groups through a wide variety of common projects devised to develop mutual respect - from Oceanic voyaging to securing the health of the homeless.

In active-citizenship learning students' projects at Salzburg University of Teacher education can be very different as students react individually to the needs of the society according to their skills and independently implement their own projects. Based on the idea of sustainability, for example, workshops are held together with disabled or disadvantaged people, clean-ups are organized, or people are consulted. To support a fairer and more inclusive world, students organize trainings, food supplies, community operas, and other types of events when they work with refugees, migrants, or other disadvantaged people, just like they become effective in caring for the elderly, when they work with them in their homes.

An amazing new field of engagement opportunities has opened up as a result of the pandemic and progress in computer science. We are now able to work locally and globally at the same time - which is both a tremendous learning opportunity and a necessity to continue to have a livable world. It is no coincidence that the United Nations Sustainable Development Goals [9] are echoed in the work of engaged citizens worldwide.

\section{Civic-mindedness and intercultural and democratic competencies}

To prepare students for their role in society and enable them to participate in a culture of democracy the Council of Europe provides a competence model showing 20 competences that enable a democratic culture (see Figure 2).

It focuses on the four principles "values, attitudes, skills, and knowledge and critical understanding" [8].

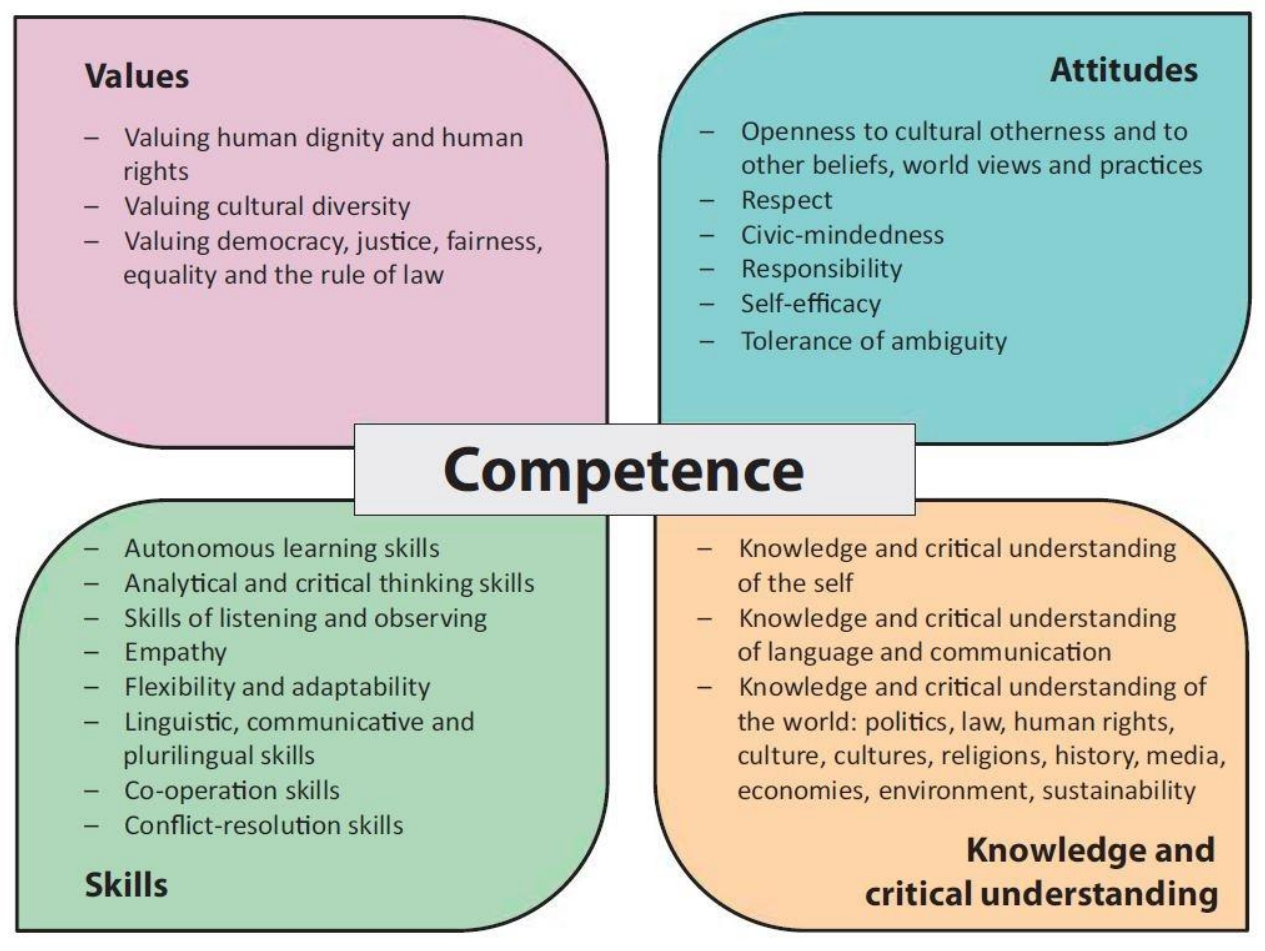

Figure 2. Twenty competences for a democratic culture [8]

Engaged pedagogies enable students to get to know different approaches to social engagement, to acquire pedagogical competence in the area of civic engagement through application-oriented teaching and by assuming social responsibility and to experience a strengthening of their civil society awareness. Dealing with social issues in different contexts requires an intercultural competence, which is also a key competence of the 21 st century [10]. This means being able to react respectfully to 
ambiguities and different intercultural situations with empathy, and flexibility, but also tolerance, supporting being able to react appropriately and efficiently to cross-cultural situations, the intercultural competence is linked with civicmindedness as well as a deeper understanding of democracy, and valuing human rights.

\section{Research Design}

The study presented here aims to ascertain students' democratic awareness and related values in SL and ACL as these pedagogies are currently practiced. Thus, the key factors to pursue for democratic education are to determine (1) whether and to what extent service learning or activecitizenship learning in higher education promotes a culture of democracy, as well as (2) whether and in what way students experience social participation when they engage with their communities. For this particular purpose, we focus on finding answers to the following key questions:

Q1. What roles do teaching and learning pedagogies like SL and ACL play for civic-mindedness and for strengthening a culture of democracy in students' attitudes towards social responsibility and acting in the public interest?

Q2. How do students practice and experience social participation?

Using a mixed-method design quantitative and qualitative data are analyzed to interpret findings. For the quantitative study we built and implemented a survey based on empirically validated tested civicmindedness scales (CMP - Civic-Minded Professional Scale, [11] and CMGS - Civic-Minded Graduate Scale, [12]), as well as subscale based on the conceptual model for a democratic culture [8]. It was designed with 38 closed questions (7 level Likert Scale from strongly disagree to strongly agree) to ascertain whether and to what extent service learning focuses on students' democratic awareness and related values. For the study 150 undergraduate students (55 from the University of Hawai'i at Mānoa, 95 from Salzburg University of Teacher Education) took part. All of them had already started with service learning or activecitizenship learning projects. To deepen our understanding of students' attitudes and perceptions, 4 undergraduate students ( 33 from the University of Hawai' $i$ at Mānoa, 51 from Salzburg University of Teacher Education) discussed key questions in small focus groups of four to five students. Transcripts were analyzed following the Documentary Method of Interpretation [13], [14] finding sequences and meaningful structures in transcripts. With the outset in Weiss, Hahn, and Norris' Civic-minded Graduate Rubric 2.0 [15], we also developed our own rubric to analyze the quality of students' attitudes as revealed in the focus group discussions.

\section{Results}

Both scales (CMP, [11] and CMGS [12]) are well suited to measure civic-mindedness. In our study we focused on a subset of these scales and devised and employed an additional subscale to study the inclination to act for the common good, based on the Council of Europe's competence model for democratic culture [8]. A subsequent Exploratory Factor Analysis (EFA) with nine items exhibited good values for all items. A clear onefactor structure for the scale "common good" resulted from the EFA. The explained variance is $58 \%$ and all factor loadings are $>.72$. The communalities are $>.52$ and a consecutive reliability analysis shows a satisfactory Cronbach's Alpha of .894. Further statistical analyses have been published [16].

In statistical tests, the .05 alpha level was used. Intercorrelations indicate civic attitudes are very strong in both the Hawai'i and Austrian samples, and students' civic-mindedness correlates with subcomponents, the Hawai'i sample even at a stronger level. The scales in the diagram (Figure 3) show the results from the survey. It shows that both engaged pedagogies (SL and ACL) promote civicmindedness in various aspects, the Hawai' $i$ sample even at a slightly stronger level. Therefore, both engaged pedagogies play a significant role regarding students' civic-mindedness and acting for the common good, as the included samples of students' voices also illustrate.

As seen in Figure 3, the Voluntary Action Scale (Austria: $\mathrm{M}=5.09 ; \mathrm{SD}=0.83$; Hawai'i: $\mathrm{M}=5.55$; $\mathrm{SD}=0.93$ ) shows that students are informed about opportunities for volunteers. They share the vision to contribute to society by getting involved within the non-profit sector. One student said, "So, I think realizing and getting involved with within the nonprofit sector, made me realize that, um... contributing to society doesn't mean you have to spend a lot of money to do that. I think if you just have like a vision and a mission and you work towards that, you can definitely contribute to society" (GD_HI_7, 107-110). 


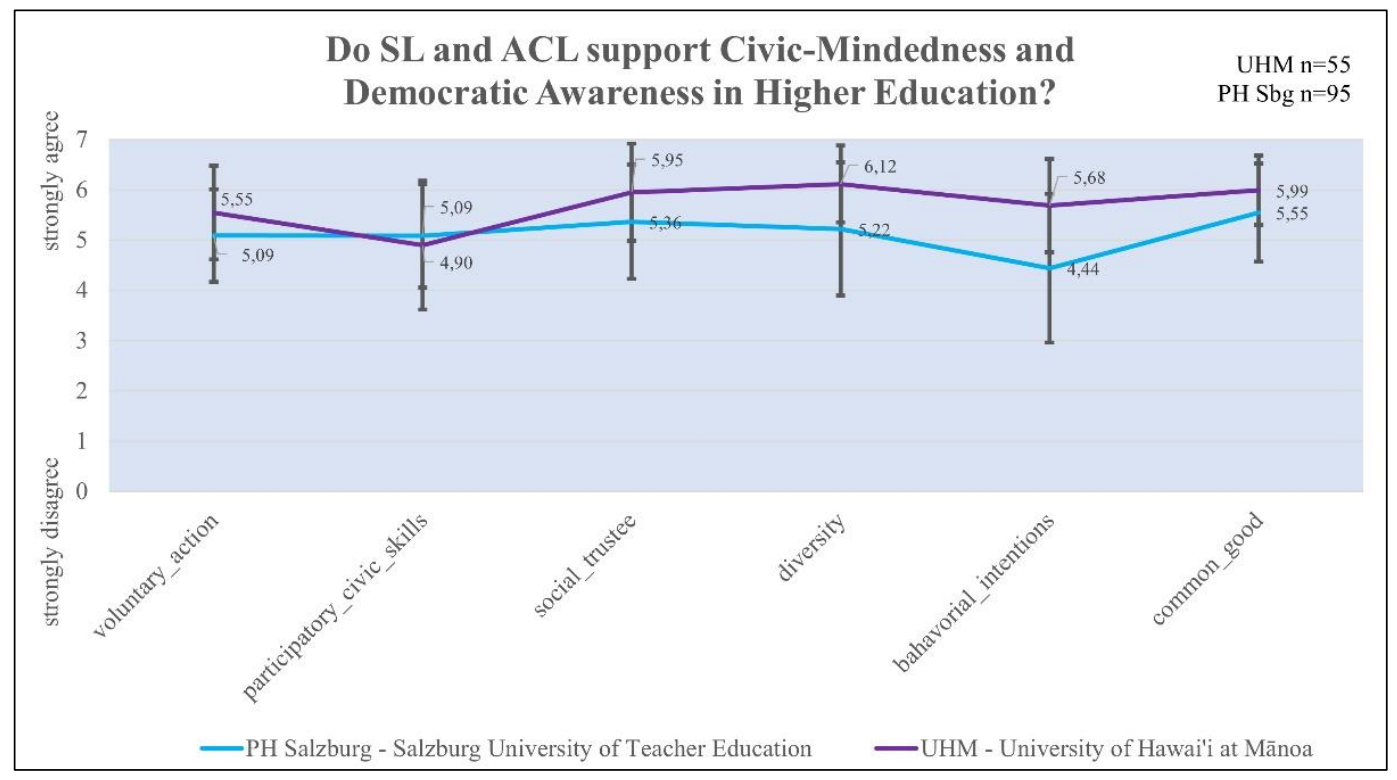

Figure 3. Service learning and active-citizenship learning support civic-mindedness in HE

Also, the scale Participatory Civic Skills (Austria: $\mathrm{M}=5.09 ; \mathrm{SD}=0.96$; Hawai'i: $\mathrm{M}=4.90$; $\mathrm{SD}=1.28$, see Figure 3) shows that students describe themselves as politically active and engaged citizens who are well informed about current public policy and current events, as one of them said, "Dedicating time, uh, to actively participate in community activities or things that benefit the community around me. Um, but also making sure that I am like vigilant in the information that's available. So, like with the news or with current research or policies? Yeah, I think that's an important part" (GD_HI_1, 46-49). They know, if they want a change, they have to be active themselves, articulated by a student: "Another part of social responsibility for me is like knowing that if I want a change, I can't hope someone else will do it. Like you said, going off that" (GD_HI_2, 43-44).

Students express that their education gives them additional responsibility to serve others, which can be seen in the Social Trustee Scale (Austria: $\mathrm{M}=5.36$; $\mathrm{SD}=1.034$; Hawai' $\mathrm{i}$ : $\mathrm{M}=5.95$; $\mathrm{SD}=0.96$ ) in Figure 3. They are aware of their responsibility to use their own strengths for the community, as one of them shared: "To be actively involved in society means to identify what your strengths are and how you can use them to help other people other than yourself' (GD_HI_6, 25-26). For them it means, "allocating the resources that you're privileged to have towards, um, causes that seek to tackle injustice" (GD_HI_1, 19-20).

Students are sensitive to diversity in a pluralistic society, which is shown in The Diversity Scale
(Austria: $\mathrm{M}=5.22 ; \mathrm{SD}=1.20$; Hawai'i: $\mathrm{M}=6.12$; $\mathrm{SD}=0.77$ ). Figure 3 shows that students appreciate opportunities to experience interaction with people different from themselves. They see cultural and ethnic diversity in the community as enrichment, for instance: "There's older people, there's people in your demographic and age and then there's even younger people. And having that blend, I feel like you learn a lot" (GD_HI_7, 71-72). Students appreciate their opportunities to experience interaction with people different from themselves. One of them said, "Connecting with different types of people and making sure that you practice like empathy and listening and being able to perceive and understand different experiences from yours" (GD_HI_1, 109-11).

Regarding the Behavioral Intentions Scale (Austria: $\mathrm{M}=4.44 ; \mathrm{SD}=1.42$; Hawai'i: $\mathrm{M}=5.68$; $\mathrm{SD}=0.93$ ) Figure 3 shows that they feel motivated also to engage in the future or act as a volunteer. In the discussion they mention "I can say I contribute in that sense of level, but what I hope to do more is to get a much more of a global scale. And I think that's something I want to try and to contribute and hope to do in my further research" (GD_HI 3, 330332). Students see that engagement develops their own personality. One of them revealed, "It creates you into more of like a selfless, altruistic person ... I think it helps you to also realize that there are other routes that you can take and maybe find other passions like that don't necessarily define you based on your nature" (GD_HI_7, 52, 53-55). 
Also acting for the common good seems to be important for students at both universities. The Common Good Scale (Austria: $\mathrm{M}=5.55 ; \mathrm{SD}=0.83$; Hawai'i: $\mathrm{M}=5.99$; $\mathrm{SD}=0.69$ ) in Figure 3 shows that students have a sense of identifying and belonging to the community. As a student expressed it, "Basically, since we're all part of society, it's our responsibility to contribute to it. So, whether that means giving back, um, and, and just basically just helping out and, and trying to make this society better because we are a part of it and we complete it as a whole" (GD_HI_2, 19-22). They are also aware of other people and of the impact of actions. One student put it like this. "Doing something not just for a paycheck or something, you're doing something that's actually going to improve lives or at the very least get people thinking more about what they can do for the community at large" (GD_HI_8, 158161). Students feel committed to fulfill responsibilities associated with their role in society, and they show a sense of civic duty to contribute to solutions, as one student shared, "And as soon as you realize like that humble moment, like, Oh, maybe I don't know everything about this, like that can really spark this chain reaction that then leads to, you know, a more complete view of the world and that understanding of positions and all those things that come along doors towards" (GD_HI_3, 300-303).

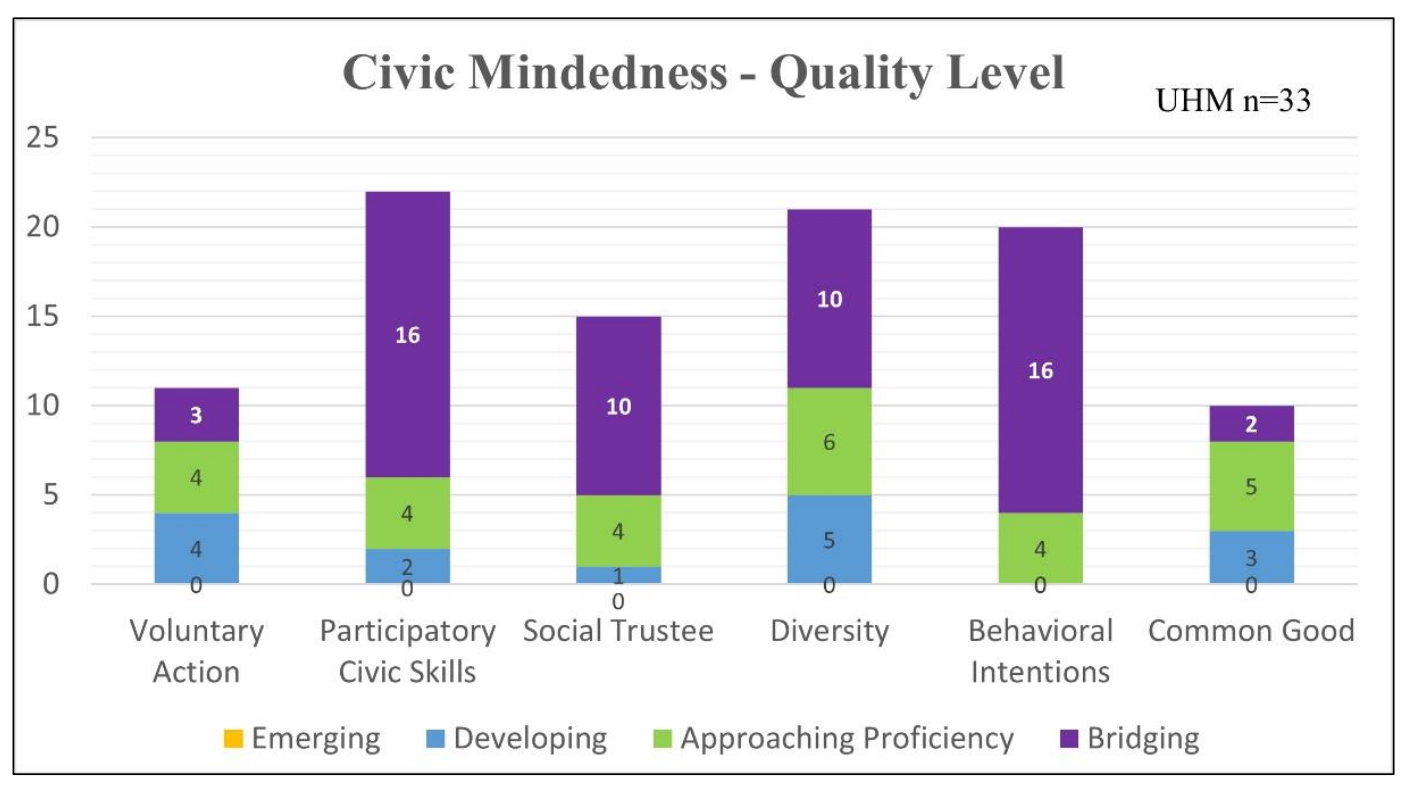

Figure 4. Quality level of civic-mindedness

Results of the data analyses from the focus group discussions are shown in the diagram above (Figure 4) corresponding to the categories used in our rubric. As the analysis of the Austrian transcripts is ongoing, Figure 4 focuses on the Hawai'i sample. The graph confirms that the students' attitudes regarding social responsibility and civic thinking are at a high level. They are not beginners. They predominantly reach the level "approaching proficiency" or they demonstrate how they are ready to and fully capable of "bridging" theory and practice to become part of solutions.

\section{Discussion and Conclusion}

The joint study introduced in this paper is part of an international cross-cultural project to learn about engaged pedagogies and their impacts on students' attitudes and values.

The purpose of this joint study is not to compare the two universities and their engaged learning outcomes as the cultural differences and social contexts cannot be compared. Furthermore, students come from different disciplines studying different majors. Rather, it is about highlighting the strengths of these two engaged pedagogies and learning from each other.

Overall, we conclude that engaged pedagogies such as service learning and active-citizenship learning can help ensure inclusive and equitable quality education and promote lifelong learning [1] when students engage in problem-solving in collaboration with their communities. Building on two empirically tested and validated civicmindedness scales (CMP - Civic-Minded 
Professional Scale, [11] and CMGS - Civic-Minded Graduate Scale, [12]) we employ a new subscale "common good" to learn about students' resulting sense of civic duty and inclination to act for the common good. Through our mixed-methods design we listened to the students to get insight into their experiences and awareness regarding civicmindedness, their democratic attitudes, and their orientation towards the common good.

We are finding that the high-impact practices of engaged pedagogies such as service learning and active-citizenship learning can play a crucial role for students' civic-mindedness, and their democratic attitude and values. The students participating in our research reach a high level of quality in the areas of participatory civic skills, being a social trustee for underprivileged people, openness for diversity issues, behavioral intentions, and acting for the common good.

Interestingly, although the survey shows that students have knowledge about volunteer work, in the focus group discussions they do not very often mention involvement or assuming leadership. They are aware of non-profit organizations and are willing to spend time for the benefit of the public, but they do not mention the non-profit sector when talking about their contributions to society. This is an area that needs additional research.

From analyzing student involvement in the projects that allow for focusing on equal opportunities in education, injustices due to social background or migration, equal rights, and civic issues around sustainability, we found evidence that students are interested in political action and social justice. It is important for them to contribute their own competencies to society, and to interact and collaborate with people from different backgrounds. They have a high level of awareness of other people and the impact of their own actions.

\section{References}

[1] E3M-Project. (2012). Green Paper. Fostering and Measuring 'Third Mission' in Higher Education Institutions https://www.dissgea.unipd.it/sites/dissgea.un ipd.it/files/Green\%20paper-p.pdf (Access Date: 30 May 2021).

[2] Geier, I., Schober, C., and Niederreiter, H. (2018). Partizipieren bedeutet miteinander und voneinander lernen. in S. Harter-Reiter, W. Plaute, and R. Schneider (Eds.), Inklusive Hochschule. pp. 123-130.

[3] Delors, J., Al Mufti, I., Amagi, I., Carneiro, R., Chung, F., Geremek, B. and Nanzhao, Z. (1996). Learning. The Treasure Within. Paris: UNESCO Publishing, pp. 22-23.
[4] Delors, J. (2013). The treasure within: Learning to know, learning to do, learning to live together and learning to be. What is the value of that treasure 15 years after its publication? International Review of Education, 59(3), pp. 319-330. https://doi.org/10.1007/s11159-013-9350-8.

[5] The National Task Force on Civic Learning and Democratic Engagement. (2012). A Crucible Moment: College Learning and Democracy's Future. Washington, DC: Association of American Colleges and Universities. pp. 13-14.

[6] Winne, P. H., and Perry, N. E. (2000). Measuring selfregulated learning. in M. Boekaerts, and P. R. Pintrich et al. (Eds.), Handbook of Self-Regulation (pp. 531-566). San Diego: Academic Press.

[7] Westheimer, J., Kahne J. (2003). Reconnecting Education to Democracy. Democratic Dialogues. Phi Delta Kappan, 85(1), pp. 8-14. https://doi.org/10.1177/0 03172170308500105.

[8] Council of Europe. (2016). Competencies for democratic culture: Living together as equals in culturally diverse democratic societies. Strasbourg: Council of Europe.

[9] United Nations. (2015). Sustainable Development Goals. http://www.un.org/sustainabledevelopment/sustai nable-development-goals/ (Access Date: 31 May 2021).

[10] Deardorff, D. K. (2006). Interkulturelle Kompetenz Schlüsselkompetenz des 21. Jahrhunderts? Gütersloh: Bertelsmann Stiftung.

[11] Hatcher, J. A. (2008). The public role of professionals. Developing and evaluating the CivicMinded Professional scale. (Doctoral dissertation). Pro Quest Dissertation and Theses, AAT 3331248.

[12] Steinberg, K. S., Hatcher, J. A., and Bringle, R. G. (2011). Civic-Minded Graduate: A North Star. https://scholarworks.iupui.edu/handle/1805/4592 (25 May 2021).

[13] Bohnsack, R. (2003). Rekonstruktive Sozialforschun -g. Einführung in qualitative Methoden (5. ed.). Opladen: Barbara Budrich Verlag.

[14] Bohnsack, R., Nentwig-Gesemann, I. and Nohl, A. (2007). Die dokumentarische Methode und ihre Forschungspraxis. Grundlagen qualitativer Sozialforschu -ng (2. ed.). Wiesbaden: VS Verlag für Sozialwissenscha -ften.

[15] Weiss, H. A., Hahn, T., and Norris, K. E. (2017). Civic-Minded Rubric 2.0. https://scholarworks.iupui.edu/ bitstream/handle/1805/13367/cmg2_FULLfinal.pdf?sequ ence $=3 \&$ isAllowed $=y$ (Access Date: 31 May 2021). 
[16] Geier, I. and Hasager, U. (2020). Do ServiceLearning and Active-Citizenship Learning support our students to live a culture of democracy? in B. Regueiro, R. G. Bringle, and M. A. Santos (Eds.), Service Learning, Educational Innovation and Social Transformation, Frontiers of Education. https://doi.org/10.3389/feduc.20 20.606326

\section{Acknowledgements}

The empirical work was supported by a Fulbright Scholarship in 2019/2020 for Dr. Ingrid Geier to conduct research at the University of Hawai'i at Mānoa. 